\title{
Stability of a Jensen's functional equation in Banach spaces
}

\section{Seyed Habib Shakoory}

Electrical and Computer Engineering Department, Seraj Higher Education Institute, Tabriz, Iran

\section{Email address:}

Habibshakoory@yahoo.com

\section{To cite this article:}

Seyed Habib Shakoory. Stability of a Jensen's Functional Equation in Banach Spaces. Pure and Applied Mathematics Journal. Vol. 3, No. 4, 2014, pp. 92-94. doi: 10.11648/j.pamj.20140304.13

\begin{abstract}
Our aim in this note is to study the Hyers -Ulam stability and we investigate the Hyers-Ulam stability of generalized Jensen's Functional Equation in Banach Spaces: $f((x+y) / 2)=(f(x)+f(y)) / 2$
\end{abstract}

Keywords: Hyers-Ulam Stability, Jensen's Functional Equation, Approximation Theory

\section{Introduction}

The Stability of Functional Equations seem to have been first studied by Ulam [5] in 1940 and solved in the next year for the Cuachy Functional Equations by Hyers [2]. In the following year, Hyers theorem gave a partial affirmative answer to the question of Ulam-Hyers theorem and it was generalized by Aoki [1]. For additive mapping by Rassias [4] and for linear mapping by considering an unbounded Cauchy difference during the past decades, several stability problems for various Functional equations have been investigated by a number of mathematicians, and we refer the reader to [cf. Gajda 1991, Gavruta 1994, Vaezi and park 2008, vaezi and zamani 2009, vaezi and dehgan 2010, Vaezi and Shakoory 2012, shakoory 2013] and also to the references cited therein. Another famous equation that is closely related to the Cauchy functional equation is Jensen's functional equation:

$$
f((x+y) / 2)=(f(x)+f(y)) / 2
$$

The first result on the stability of the classical Jensen's functional equation was given by Kominek [3]. In this paper, we investigate the Hyers-Ulam stability of the Jensen's functional equation for linear bounded mapping from Banach spaces in to Banach spaces.

\section{Main Results}

\subsection{Definition}

Let $\mathrm{X}$ be a set. A function $\mathrm{d}: \mathrm{X} \times \mathrm{X} \rightarrow[0, \infty)$ is called a generalized metric on $\mathrm{X}$ if $\mathrm{d}$ satisfies:

(1) $d(x, y)=0$ if and only if $x=y$.

(2) $d(x, y)=d(y, x)$ for all $x, y \in X$

(3) $d(x ; z) \leq d(x, y)+d(y, z)$ for all $x, y, z \in X$.

\subsection{Definition}

A (real) complex normed space is a (real) complex vector space $\mathrm{X}$ together with a map: $\mathrm{X} \rightarrow \mathrm{R}$, called the norm and denoted $\|$.$\| , such that$

(1) $\|x\| \geq 0$ for all $x \in X$, and $\|x\|=0$ if and only if $x$ $=0$.

(2) $\|\mathrm{ax}\|=|\alpha|\|\mathrm{x}\|$, for all $\mathrm{x} \in \mathrm{X}$ and all $\alpha \in \mathrm{R}$ or (C).

(3) $\|x+y\| \leq\|x\|+\|y\|$, for all $x, y \in X$.

\subsection{Definition}

A complete normed space is called a Banach space. Thus, a normed space $\mathrm{X}$ is Banach space if every Cuchy sequence in $\mathrm{X}$ converges (where $\mathrm{X}$ is given the metric space structure as outlined above).

\subsection{Definition}

Let $\mathrm{W}$ be a Banach space. $\mathrm{f}$ a differentiable map on $\mathrm{V}$ into $\mathrm{W}$ so that

$$
\|\mathrm{f}((\mathrm{x}+\mathrm{y}) / 2)-\mathrm{f}(\mathrm{x} / 2)-\mathrm{f}(\mathrm{y} / 2)\| \mathrm{B} \leq \varepsilon
$$

for all $\mathrm{x}, \mathrm{y} \in \mathrm{V}$,we say that the Hyers-Ulam stability holds for $\mathrm{f}$, if there exist a $\mathrm{K}>0$ and a differentiable map $\mathrm{T}$ on $\mathrm{V}$ into $\mathrm{W}$ such that 


$$
\|\mathrm{T}((\mathrm{x}+\mathrm{y}) / 2)-\mathrm{T}(\mathrm{x} / 2)-\mathrm{T}(\mathrm{y} / 2)\| \mathrm{B} \leq \varepsilon
$$

and

$$
\|\mathrm{f}(\mathrm{x})-\mathrm{T}(\mathrm{x})\| \mathrm{B} \leq \mathrm{K} \varepsilon
$$

holds for every $\mathrm{x}, \mathrm{y} \in \mathrm{V}$,we call such $\mathrm{K}$ a Hyers-Ulam stability constant for Jensen's functional equation:

$$
f((x+y) / 2)=(f(x)+f(y)) / 2
$$

Now, the main result of this work is given in the following theorem.

\subsubsection{Theorem}

Let $\mathrm{V}$ and $\mathrm{W}$ be Banach spaces. A mapping $\mathrm{f}: \mathrm{V} \rightarrow \mathrm{W}$ with $f(0)=0$ satisfies the functional equation:

$$
2 n f\left((x 1+x 2+\ldots+x 2 n) /\left(2^{n}\right)\right)=\sum_{i=1}^{2^{n}} f(x i)
$$

for all $\mathrm{x} 1, \mathrm{x} 2, \ldots, \mathrm{x} 2 \mathrm{n} \in \mathrm{V}$ if and only if the mapping $\mathrm{f}: \mathrm{V}$ $\rightarrow$ W satisfies the additive Cauchy equation $\mathrm{f}(\mathrm{x}+\mathrm{y})=\mathrm{f}(\mathrm{x})$ $+\mathrm{f}(\mathrm{y})$ for all $\mathrm{x}, \mathrm{y} \in \mathrm{V}$.

Proof:

Assume that a mapping f: $\mathrm{V} \rightarrow \mathrm{W}$ satisfies

$$
2^{\mathrm{n}} \mathrm{f}\left((\mathrm{x} 1+\mathrm{x} 2+\ldots+\mathrm{x} 2 \mathrm{n}) /\left(2^{\mathrm{n}}\right)\right)=\sum_{\mathrm{i}=1}^{2^{\mathrm{n}}} \mathrm{f}(\mathrm{xi})
$$

Put

$$
x_{1}+x_{2}+\ldots .+x_{2^{n-1}}=x
$$

and

$$
x_{2^{n-1}}+1=x_{2^{n-1}}+2=\ldots=x_{2^{n}}=y
$$

in

$$
2^{n} f((x 1+x 2+\ldots+x 2 n) /(2 n))=\sum_{i=1}^{2^{n}} f(x i)
$$

then

$$
2^{n} f((x+y) /(2))=2 n-1 f(x)+2 n-1 f(y)
$$

for all $\mathrm{x}, \mathrm{y} \in \mathrm{V}$. So

$$
2 f((x+y) /(2))=f(x)+f(y)
$$

for all $\mathrm{x}, \mathrm{y} \in \mathrm{V}$. Hence $\mathrm{f}$ is additive. The convergence is obvious.

\subsubsection{Theorem}

Let $\mathrm{V}$ and $\mathrm{W}$ to be two Banach spaces with norms $\|$. and $\|$.$\| , respectively. Consider \mathrm{f}: \mathrm{V} \rightarrow \mathrm{W}$ to be a mapping such that $\mathrm{f}(\mathrm{t} \mathrm{x})$ is continuous in $\mathrm{t} \in \mathrm{R}$ for each fixed $\mathrm{x} \in \mathrm{V}$. Assume that there exist constants $\varepsilon \geq 0$ and $p \in[0,1)$ such that:

$$
\|f((x+y) / 2)-f(x / 2)-f(y / 2)\| \leq \varepsilon(\|x / 2\| p+\|y / 2\| p
$$

for any $\mathrm{x}, \mathrm{y} \in \mathrm{V}$. Then there exist a unique R-Linear mapping $\mathrm{T}: \mathrm{V} \rightarrow \mathrm{W}$ such that :

$$
\|\mathrm{f}(\mathrm{x})-\mathrm{T}(\mathrm{x})\| \leq \varepsilon\|\mathrm{x}\| \mathrm{p}(4 /(2-2 \mathrm{p}))
$$

for any $\mathrm{x} \in \mathrm{V}$, where Hyers-Ulam stability constant is for Jensen's functional equation.

Proof

Set

$$
1 / 2 T(x)=\lim _{n \rightarrow \infty} 1 / 2^{n}\left[f\left(2^{n} x\right)\right]
$$

and multiplying the assumed equation

$$
\|f((x+y) / 2)-f(x / 2)-f(y / 2)\| \leq \varepsilon(\|x / 2\| p+\|y / 2\| p
$$

to $2^{\mathrm{n}+1}$ :

$$
\begin{aligned}
\| f\left[2^{n}(x+y)\right] & -f\left[2^{n}(x)\right]-f\left[2^{n}(y)\right] \| \\
& \leq \varepsilon\left(\left\|2^{n} x\right\| p+\left\|2^{n} x\right\| p\right) \\
& \left.=2^{n} p \varepsilon\|x\| p+\|y\| p\right)
\end{aligned}
$$

Therefore

$$
\begin{gathered}
1 / 2^{\mathrm{n}}\left\|\mathrm{f}\left[2^{\mathrm{n}}(\mathrm{x}+\mathrm{y})\right]-\mathrm{f}\left[2^{\mathrm{n}}(\mathrm{x})\right]-\mathrm{f}\left[2^{\mathrm{n}}(\mathrm{y})\right]\right\| \leq 2^{\mathrm{n}}(\mathrm{p}-1) \\
\varepsilon(\|\mathrm{x}\| \mathrm{p}+\|\mathrm{y}\| \mathrm{p})
\end{gathered}
$$

Or

$$
\begin{gathered}
\lim _{n \rightarrow \infty} 1 / 2^{n}\left\|f\left[2^{n}(x+y)\right]-f\left[2^{n}(x)\right]-f\left[2^{n}(y)\right]\right\| \\
\leq \lim _{n \rightarrow \infty} 2^{n}\left(p-{ }^{1}\right) \varepsilon(\|x\| p+\|y\| p)
\end{gathered}
$$

Or

$\left\|\lim _{n \rightarrow \infty} 1 / 2^{n} f\left[2^{n}(x+y)\right]-\lim _{n \rightarrow \infty} 1 / 2^{n} f\left[2^{n}(x)\right]-\lim _{n \rightarrow \infty} 1 / 2^{n} f\left[2^{n}(y)\right]\right\|=0$

Or

$$
\|\mathrm{T}((\mathrm{x}+\mathrm{y}) / 2)-\mathrm{T}(\mathrm{x} / 2)-\mathrm{T}(\mathrm{y} / 2)\|=0
$$

For any $\mathrm{x}, \mathrm{y} \in \mathrm{V}$.

To prove stability our claim that:

$$
\left\|f\left(2^{n} x\right) / 2^{n}-f(x)\right\| \leq \varepsilon\|2 x\| p \sum_{m=0}^{n-1} 2^{m}\left(p-{ }^{1}\right)
$$

For any integer $\mathrm{n}$, and some $\varepsilon \geq 0$. The verification of above equation following by induction on $\mathrm{n}$. Indeed the case $\mathrm{n}=1$ is clear because by the hypothesis we can find $\varepsilon$, that is greater or equal to zero, and $p$ such that $0 \leq p<1$ with:

$$
\|f(2 x) / 2-f(x)\| \leq \varepsilon\|2 x\| p
$$

Assume now that 


$$
\left\|f\left(2^{n} x\right) / 2^{n}-f(x)\right\| \leq \varepsilon\|2 x\| p \sum_{m=0}^{n-1} 2^{m}\left(p^{-1}\right)
$$

holds and we want to prove it for the case $\mathrm{n}+1$. However this is true, because by

$$
\left\|f\left(2^{n} x\right) / 2^{n}-f(x)\right\| \leq \varepsilon\|2 x\| p \sum_{m=0}^{n-1} 2^{m}\left(p^{-1}\right)
$$

We obtain

$$
\left\|\mathrm{f}\left(2^{\mathrm{n}} .2 \mathrm{x}\right) / 2^{\mathrm{n}}-\mathrm{f}(\mathrm{x})\right\| \leq \varepsilon\|4 \mathrm{x}\| \mathrm{p} \sum_{\mathrm{m}=0}^{\mathrm{n}-1} 2^{\mathrm{m}}\left(\mathrm{p}^{-1}\right)
$$

Therefore

$$
\left\|f\left(2^{n} .2 x\right) / 2^{n}+{ }^{1}-1 / 2 f(2 x)\right\| \leq \varepsilon\|2 x\| p \sum_{m=0}^{n-1} 2^{m}\left(p^{-1}\right)
$$

By the triangle inequality we obtain:

$$
\begin{gathered}
\left\|\mathrm{f}\left(2^{\mathrm{n}+1} \mathrm{x}\right) / 2^{\mathrm{n}+1}-\mathrm{f}(\mathrm{x})\right\| \leq \| 1 / 2^{\mathrm{n}+1} \mathrm{f}\left(2^{\mathrm{n}+1} \mathrm{x}\right)-1 / 2 \mathrm{f}(2 \mathrm{x}) \\
\|+\| 1 / 2 \mathrm{f}(2 \mathrm{x})-\mathrm{f}(\mathrm{x})\|\leq \varepsilon\|\|2 \mathrm{x}\| \mathrm{p} \sum_{\mathrm{m}=0}^{\mathrm{n}-1} 2^{\mathrm{m}}\left(\mathrm{p}-{ }^{-1}\right)
\end{gathered}
$$

and is valid for any integer $\mathrm{n}$. It follows then that

$$
\left\|\mathrm{f}\left(2^{\mathrm{n}} \mathrm{x}\right) / 2^{\mathrm{n}}-\mathrm{f}(\mathrm{x})\right\| \leq \varepsilon \quad\|2 \mathrm{x} \quad\|{ }^{\mathrm{p}} .(2 /(2-2 \mathrm{p}))
$$

because $\sum_{\mathrm{m}=0} \infty 2^{\mathrm{m}}\left(\mathrm{p}^{-1}\right)$ converges to $(2 /(2-2 \mathrm{p}))$, as $0 \leq$ $\mathrm{p}<1$ we obtain

$$
\|\mathrm{T}(\mathrm{x})-\mathrm{f}(\mathrm{x})\| \leq \varepsilon \quad\|2 \mathrm{x} \quad\| \mathrm{p} .(2 /(2-2 \mathrm{p}))
$$

Hence

$$
\|\mathrm{T}(\mathrm{x})-\mathrm{f}(\mathrm{x})\| \leq \varepsilon \quad\|\mathrm{x} \quad\| \mathrm{p} .(4 /(2-2))
$$

which completes the proof.

\section{References}

[1] T. Aoki, on the stability of the linear transformation in banach spaces, j. Math. Soc.Japan, 2(1950)64-66.J. Clerk Maxwell, A Treatise on Electricity and Magnetism, 3rd ed., vol. 2. Oxford: Clarendon, 1892, pp.68-73.

[2] I D. H. Hyers."on the stability of the linear functional equation, Proc. Nat. Acad. Sci. U.S.A.27(1941),222-224.

[3] Z. Kominek, on a local stability of the jensen functional EQUATION, Demonstratio Math., 22 (1989),499-507.

[4] R TH.M. Rassiass, on the stability of the linear mapping in Banach spaces, Proc. Amer. Math. Soc. 72(1978),297-300.

[5] M. Ulam, A Collection of Mathematical Problems, Interscience Tracts in Pure and Applied Mathematics, no. 8, Interscience, New York, NY, USA, 1960. 1. 